\title{
Carbon isotope variations across diamonds with clear and opaque growth zones measured by secondary ion mass spectrometry
}

\author{
Graham Janson $^{1}$, Karlis Muehlenbachs ${ }^{1}$, Thomas Stachel ${ }^{1}$, and David Eichenberg ${ }^{2}$ \\ ${ }^{I}$ Earth and Atmospheric Sciences, University of Alberta, Edmonton, T6G 2E3, Canada \\ ${ }^{2}$ Diavik Diamond Mines Inc., Yellowknife, X1A 2P8, Canada
}

\section{Introduction}

The occurrence of coated diamonds has been documented in Group I kimberlites worldwide, most notably at Mbuji Mayi in the Democratic Republic of Congo where they comprise up to $90 \%$ of the production (Kamiya and Lang, 1965). At Diavik Diamond Mines in the Central Slave Craton of Northern Canada, coated stones make up approximately $6 \%$ of the production. Coated diamonds record unique and unusual conditions of diamond formation and therefore represent a fount of information on mantle geochemistry. By comparison to inclusion bearing gem diamonds, coated diamonds have, however, been little studied.

Coated diamonds typically comprise a transparent core surrounded by a light to dark grey translucent to opaque coat. The opacity of the coat is due to the presence of abundant micron-scale fluid inclusions spanning a continuum from carbonatitic (Schrauder and Navon, 1994) to saline (Izraeli et al., 2001) compositions, with rare silicic fluids (Klein-BenDavid et al., 2007). Growth of opaque diamond coats has long been proposed to be related to kimberlite magmatism (e.g. Swart et al., 1983, Boyd et al., 1994, Rondeau et al., 2007) but the connection thus far remains tenuous.

Here we present a detailed study of the carbon isotopic composition of diamond coats at previously unreported spatial resolution, along with resultant implications for growth mechanisms of diamond coats. The carbon isotope data are consistent with growth of diamond coats from an oxidized carbon-bearing fluid, such as would be exsolved from upwelling kimberlite magma.

Secondary ion mass spectrometry (SIMS) was used to measure carbon isotopic composition across diamond cores and coats in transects perpendicular to growth planes (i.e. parallel to the direction of diamond growth) with a point spacing of 30 to $100 \mu \mathrm{m}$. SIMS measurements at high spatial resolution eliminate the averaging of isotopic heterogeneities occurring with conventional sealed-tube techniques, allowing for interpretation of growth mechanisms based on microscale variations of $\delta^{13} \mathrm{C}$.

\section{Samples}

Seven coated diamonds were selected from a suite of 37 samples for analysis by SIMS. The most common morphology in the larger suite is a transparent core surrounded by a dark grey coat up to $1 \mathrm{~mm}$ thick. One sample has clear diamond outside of opaque, and one has no obvious core but exhibits multiple zones of light and dark diamond coat, suggestive of cyclic or episodic growth (Fig. 1). To prepare the diamonds for SIMS analysis they were bisected approximately parallel to $\{100\}$, polished, and Au coated.

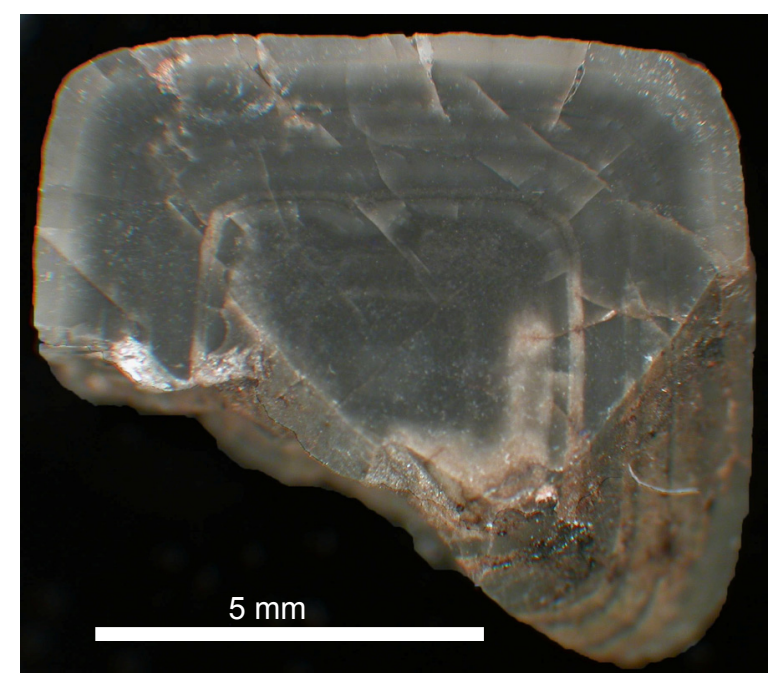

Figure 1: Sample GJDV-1, a "tree ring diamond" (hailstone boart), showing alternating light and dark bands of diamond on a surface polished parallel to $\{100\}$.

\section{Results}

Carbon isotopic composition measured by SIMS tends to be homogenous within cores of individual diamonds, with $\delta^{13} \mathrm{C}$ approximately $-5 \pm 1 \%$. This mean value agrees well with both conventional sealed-tube gas source measurements of diamonds from the same sample suite and with the worldwide mode in diamond isotopic composition reported by Cartigny (2005). Diamond coats measured by conventional techniques have $\delta^{13} \mathrm{C}$ of approximately $-7 \%$, also in agreement with the worldwide mode for coated diamonds reported by Cartigny (2005). 
As shown in Figure 2, carbon isotopic composition as measured by SIMS typically is relatively constant through diamond cores but abruptly decreases by up to $4 \%$ at the core-coat interface. Outwards from the interface diamonds typically exhibit a gradational increase in $\delta^{13} \mathrm{C}$ from approximately $-9 \%$ to $-6.5 \%$ o over several hundred micrometres.

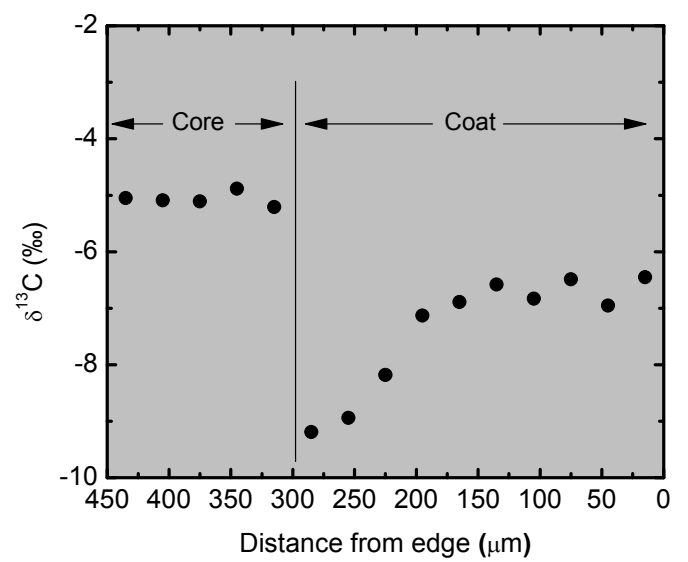

Figure 2: SIMS profile of $\delta^{13} \mathrm{C}$ across the clear core and opaque coat of sample GJDV-8b, showing a typical sharp decrease at the core-coat interface followed by a gradational outward increase. Measurement error for $\delta^{13} \mathrm{C}$ is $\pm 0.1 \%$.

Complexly zoned coats such as the hailstone boart shown in Figure 1 exhibit one or more visually distinct layers, and have corresponding complexities in their $\delta^{13} \mathrm{C}$ profiles. This type of zonation and corresponding SIMS profile are shown in Figure 3.
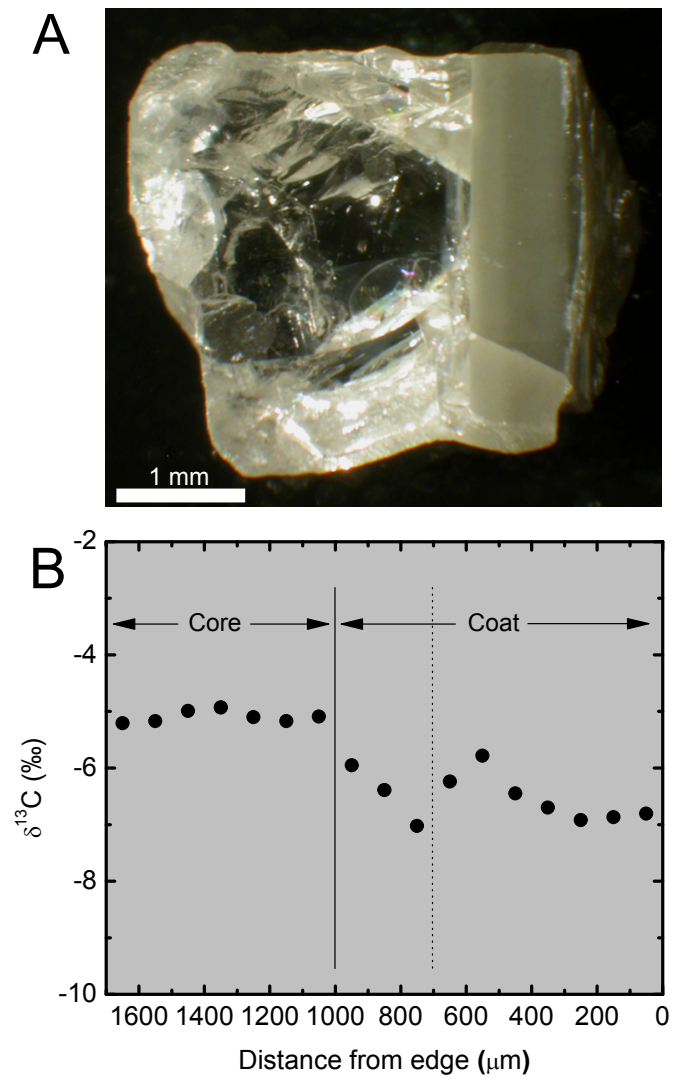

Figure 3: A: Photomicrograph of a polished slab of sample GJDV-9. Note the visually distinct zonation between lighter and darker layers within coat, indicated on the plot by the dashed line. B: SIMS profile of $\delta^{13} \mathrm{C}$ across GJDV-9.

\section{Discussion and Conclusions}

According to isotope fractionation coefficients reported by Bottinga (1969), diamond precipitated from a $\mathrm{CO}_{2}-$ bearing (i.e. oxidized) fluid at $1000^{\circ} \mathrm{C}$ will be depleted in ${ }^{13} \mathrm{C}$ by approximately $4 \%$ relative to the original fluid. Continued growth of diamond in a closed system causes a parallel evolution (offset by 4\%o) of the diamond and the parent $\mathrm{CO}_{2}$-fluid towards increasingly ${ }^{13} \mathrm{C}$ enriched compositions (Deines, 1980).

Assuming closed system conditions, evolution of a parent fluid can be described by the Rayleigh equation:

$$
\delta^{13} C_{\mathrm{CO}_{2}}=1000(\alpha-1) \times \ln (f)+\delta^{13} C_{\mathrm{CO}_{2}}^{o}
$$

where $\alpha$ is a constant isotopic fractionation factor between $\mathrm{CO}_{2}$ and diamond under specified pressuretemperature conditions, and $f$ is the fraction of carbon remaining in the parental fluid phase. Since $\delta^{13} \mathrm{C}_{\mathrm{CO} 2}=$ $\delta^{13} \mathrm{C}_{\text {diamond }}+4 \%$ we can calculate both the initial carbon isotopic composition of the parent fluid $\left(\delta^{13} \mathrm{C}^{0}\right)$ and the fluid in equilibrium with diamond for each SIMS spot. Using these calculated values of $\delta^{13} \mathrm{C}_{\mathrm{CO} 2}$ for each spot, we calculate the degree of depletion of carbon in the parent fluid (Fig. 4) using Equation 1.

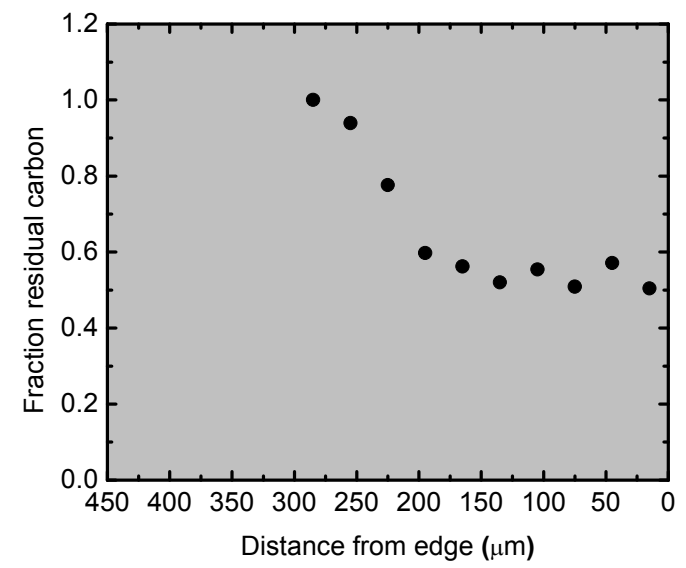

Figure 4: Rayleigh model calculation of the fraction of residual carbon in the fluid in equilibrium with sample GJDV-8b. The SIMS $\delta^{13} \mathrm{C}$ profile for this sample is shown in Figure 2.

Initial precipitation of diamond coats at $-9 \%$ agrees well with Rayleigh fractionation from an oxidized fluid containing $\mathrm{CO}_{2}$ with an initial $\delta^{13} \mathrm{C}$ of $-5 \%$. Additionally, modeling the growth of diamond coats within a closed system predicts the observed evolution towards higher values of $\delta^{13} \mathrm{C}$. Mass balance constraints are not violated by our Rayleigh model calculations as shown in Figure 4, which indicates a depletion of carbon in the diamond precipitating fluid by only up to $50 \%$.

The abundance of carbonatitic fluid inclusions in diamond coats (Schrauder and Navon, 1994) further supports the hypothesis that their parent fluids are oxidized. This condition is met by the fluids exsolving from upwelling kimberlite magma: kimberlite is 
predicted to dissolve large amounts of $\mathrm{CO}_{2}$ at high pressures, which subsequently begins to exsolve in significant quantities during ascent through the deep lithospheric mantle (Brey et al., 1991). Failed "protokimberlite" intrusions in the deep lithospheric mantle also are commonly assumed to be responsible for the formation of megacrysts found in kimberlites. Since most opaque diamond occurs as coats surrounding transparent cores, we propose that $\mathrm{CO}_{2}$-bearing fluids exsolving from upwelling kimberlite magma encounter pre-existing seed diamonds within the lithospheric mantle, resulting in precipitation of diamond coats. The high abundance of fluid inclusions in coats and precipitation occasionally switching into a rough growth regime imply rapid growth, indicative of a high degree of supersaturation of carbon. Furthermore, growth must be sufficiently rapid with respect to fluid infiltration so as to approach closed system behaviour, as indicated by the agreement of SIMS profiles with Rayleigh model predictions. Diamond precipitation from a $\mathrm{CO}_{2}$-rich fluid must involve redox reactions that likely are driven by a reduced character of the deep cratonic lithosphere (Haggerty and Tompkins, 1983).

Complexly zoned diamond coats such as those shown in Figures 1 and 3A likely record multiple events of diamond overgrowth, and are best explained as records of repeated replenishment of metasomatic fluid, possibly evolving from multiple failed proto-kimberlite intrusions.

\section{References}

Bottinga, Y., 1969. Carbon isotope fractionation between graphite, diamond and carbon dioxide. Earth and Planetary Science Letters, 5: 301-307.

Boyd, S.R., Pineau, F., and Javoy, M., 1994. Modelling the growth of natural diamonds. Chemical Geology, 116: $29-42$

Brey, G.P., Kogarko, L.N., and Ryabchikov, I.D., 1991. Carbon dioxide in kimberlitic melts. Neues Jarbuch Für Mineralogie-Monatshefte, 4: 159-168.

Cartigny, P., 2005. Stable isotopes and the origin of diamond. Elements, 1: 79-84

Deines, P., 1980. The carbon isotopic composition of diamonds: relationship to diamond shape, colour, occurrence and vapor composition. Geochimica et Cosmochimica Acta, 44: 943-961.

Haggerty, S.E., and Tompkins, L.A., 1983. Redox state of earth's upper mantle from kimberlitic ilmenites. Nature, 303: 295-300.

Izraeli, E.S., Harris, J.W., and Navon, O., 2001. Brine inclusions in diamonds: a new upper mantle fluid. Earth and Planetary Science Letters, 187: 323-332

Kamiya, Y., and Lang, A.R., 1965. On the structure of coated diamonds. Philosophical Magazine, 11: 347-356.
Klein-BenDavid, O., Izraeli, E.S., Hauri, E., and Navon, O., 2007. Fluid inclusions in diamonds from the Diavik mine, Canada and the evolution of diamondforming fluids. Geochimica et Cosmochimica Acta, 71: 723-744.

Rondeau, B., Fritsch, E., Moore, M., Thomassot, E., and Sirakian, J.-F., 2007. On the growth of natural octahedral diamond upon a fibrous core. Journal of Crystal Growth, 304: 287-293.

Schrauder, M., and Navon, O., 1994. Hydrous and carbonatitic mantle fluids in fibrous diamonds from Jwaneng, Botswana. Geochimica et Cosmochimica Acta, 58: 761-771.

Swart, P.K., Pillinger, C.T., Milledge, H.J., and Seal, M., 1983. Carbon isotopic variation within individual diamonds. Nature, 303: 793-795. 